\title{
Clinical medicine, public health and ecological health: a new basis for education and prevention?
}

Bernhard Schaller, Nora Sandu

University of Oradea, Romania

Submitted: 29 June 2010

Accepted: 14 September 2010

Arch Med Sci 2011; 7, 4: 541-545

DOI: 10.5114/aoms.2011.24117

Copyright @ 2011 Termedia \& Banach
Corresponding author:

Prof. Bernhard Schaller MD,

DSC

University of Oradea

Romania

E-mail:

skull_base_surgery@yahoo.de

\begin{abstract}
In contrast to public health and the resolution to further increase the health care of the whole community in regions worldwide, current clinical medicine has its limits. Further improvement in public health - rather than individual diseases - can only be achieved by integrating new views into treatment. Some years ago, the concept of biopsychosocial medicine was integrated into patient treatment and is now generally accepted. Therefore the author describes here a new dimension to treatment and presents substantial evidence to include ecological health in this already existing concept. The problem of community education is discussed.
\end{abstract}

Key words: education, public health, ecological health, clinical medicine.

\section{Introduction}

Over the centuries, the great challenge of medicine has been to find ways to save human lives, to make and keep people healthy, and to prolong human life. Modern medicine has greatly succeeded in controlling, avoiding and even eliminating diseases. To achieve this goal, there have been developed for example extraordinary surgical techniques [1], including procedures to transplant vital organs [2]. Implicit in such medical achievement has been the basic concept that mankind is a separate entity, a little apart from and a little above other forms of life: human beings are the crown of life on Earth. Until now, medicine indeed has considered the natural environment per se as important only when it became obvious that it was directly affecting the health of mankind [3]. One question that should be posed in this context is whether there is, or should be, any evidence that clinical medicine and public environmental or ecological health can be separated. We have therefore tried to give an overview about the fact that ecological health should be integrated into already existing biopsychosocial medicine.

\section{Clinical medicine, public health and ecology}

The fundamental importance of ecology to medicine - and the terrible price that must be paid when it is ignored - is being thrust upon physicians in three different and highly disturbing ways. First of all, we are seeing today a tremendous increase in the kinds and numbers of diseases which are brought about directly by pollution and poisoning of mankind's environment. Secondly, medicine is inadvertently responsible for new 
disease conditions because of its innocent and wellmeaning manipulation of the environment. But perhaps most serious of all, it is evident that medicine is directly responsible for some of the enormous human problems now facing mankind. By considering mankind apart from his natural environment, by tampering with and attempting to control certain fundamental ecological laws, medicine may well be hastening man's death rather than increasing his long-term chances for survival. These three points show clearly that the triad "clinical medicine", "public health" and "ecology" cannot be separated today, but has to be an integrated entity if we are to advance to cure our patients.

\section{Education to improve knowledge}

At the risk of oversimplification, and without wanting to put too fine a point on some of the details, it is worthwhile thinking across the spectrum of clinical medicine, public health, and ecological health with respect to the focus on education and prevention. It seems to be the right time to think about such things as it is now generally accepted that the environment may have a certain influence on public health. But the differences in focus on this topic are in many ways self-evident, although there is considerable overlap across the categories. Clinical medicine focuses primarily on the individual patient, public health on communities, and ecological health on those plus the entire ecosystems. Relevant time frames in clinical medicine are usually single lifetimes or perhaps two generations, while public health and ecological health gaze further into the future and the past, ultimately reaching even evolutionary time scales. These facts of knowledge have to be brought to the public to better understand the connection between clinical medicine, public health and the environment. To better understand this, we have to take into consideration the improvement of clinical medicine during the last century, which goes hand in hand with the increased environmental pollution.

\section{Improvement in clinical medicine in the context of ecology}

Without any doubt, scientific and medical understanding, public education, new and improved treatments for disease based on new technologies, and public health interventions during the $20^{\text {th }}$ century lengthened human life and dramatically reduced human morbidity and mortality from many diseases in many parts of the world (see for example [4-6]). But some of these advances come at considerable cost, and the benefits are not equally distributed. Public health systems charged with creating healthful conditions for all have suffered in competition with technologically intensive health care aimed at individual consumers. The above described advances being a reality during the last century, along with other technological achievements during the same time frame, did not, however, benefit all species and ecological systems. Current health care systems substantially struggle to keep up with the changing patterns of various diseases that result both from a rapidly changing and degraded Earth and from the way people live. New and old diseases spread with increasing speed within and across national borders. Just looking close to home, medical technologies and medical care consume large amounts of natural resources, produce a large and toxic waste stream, but also consume electricity, and pollute the air, water, sediments, and soils with mercury, dioxin, toxic flame retardants, pesticides, and a variety of pharmaceuticals. All these new circumstances have revolutionized human life in industrialized countries during the last year.

\section{Changes of food intake}

While providing the population of highly industrialized countries with a relatively inexpensive and abundant food supply, agricultural practices widely adopted during the $20^{\text {th }}$ century additionally have changed the nutritive value of food, severely degraded the environment with loss of topsoil, soil fertility, and biodiversity as well as polluted surface and groundwater with nitrates and pesticides, and caused socioeconomic distress in many rural areas.

Current food production and delivery systems, dominated by vertically integrated corporate agribusinesses, large commodity markets in corn, soybeans, and wheat, industrial scale beef, pork, and poultry production, and dependence on fossil fuels have resulted in dramatic changes in human food intake over the past $50-75$ years. However, these changes are partly influenced by environmental pollution and have also changed the incidence of certain diseases.

\section{Changes of diseases because of environment}

While progress in the treatment or elimination of some diseases has been dramatically increased $[7,8]$, new patterns of human disease have also emerged from the mix of new technologies and social practices, including increases in asthma, learning disabilities, autism, chronic degenerative diseases [9], some malignancies, infertility, and obesity.

Life as we know it depends substantially on ecological systems that have been severely degraded over the past century. Worldwide, soil, water, and air quality, fisheries, forests, pollinators, 
wetlands, coral reefs, and biological diversity are under severe stress, in some cases beyond the tipping point of no return.

Ecological medicine is an attempt to address these realities by integrating clinical medicine with public and ecosystem health. But of course, beyond scope and scale, ecological medicine raises new questions about education and scientific understanding.

\section{Ecology as part of the story}

Medical practitioners all over the world advocate for individual people and families. Public health practitioners advocate for the public - for communities and populations of people - drawing in social, environmental, and economic factors as they impact the health of humans. Ecological medicine therefore advocates for ecological health and includes, but does not focus primarily on, the health of humans, to the exclusion of other species and ecosystems. During the last years, ecology has become more and more a fundamental part of clinical medicine.

In addition, medicine can learn much from the recognition and understanding of the importance of ecology as a broad science. The science of ecology studies and relates the interlocking and interacting components of biological systems. Medicine is one of the most important of all those components. By treating medicine as a broad factor in human survival, by enlarging its concepts to include public health on the wide, long-term scale, the role of medicine in ecology can assume an even more important status. Both clinical medicine and ecology can therefore be connected with public health, the third factor of the triad that constitutes mankind's health on Earth.

\section{Public health}

Public health engages the tension within what is best for individuals and what is best for communities and populations of people. A number of ethical traditions are relevant to public health [10], including communitarians, civil liberties, human rights, social justice, and environmental justice, among others. From the communitarian perspective, public health ethics are based on the recognition that individual liberty and indeed human existence rely heavily upon the interdependent and overlapping communities to which all of us belong [11].

The exclusive pursuit of private interest erodes the network of social environments on which we all depend. Individual autonomy depends upon the active maintenance of the institutions of civil society. Community flourishing depends on individual contributions to shared projects. A spirit of solidarity supports community members who are less well off. The fundamental idea of the commons finds expression. Here tensions begin to arise between individual and public interests. Arguments for social justice run into disagreements about the rights of individuals or limited resources. There may be conflicting views about what is in a child's best interest or whether or not the interests of future generations should even be considered. This responsibility to subsequent generations is one basis of ecological medicine.

\section{Ecological medicine}

Ecological medicine addresses the interactions between the individual and the environment and their health consequences - both the impact of environmental factors on the individual, and that of each individual's actions on the environment, upon which we all depend. Ecological medicine extends beyond humans to include other species and ecological systems more generally [12]. Ecological medicine focuses even more on relationships and encounters more fundamental ethical tensions. Here we are concerned about our relationships not only with each other, but with other species, the land, water, atmosphere, forests, soil, and the like. A human rights perspective suddenly seems narrow. Some people make efforts to extend a rights-based approach to other species and ecosystems. But a rights-based approach is one of contracts and negotiations. Organisms and systems that cannot speak the language of rights do not get to sit at the negotiating table.

Ecological medicine is based on the simple premise that the health of the individual is integrally connected to the health of the habitat. Kenny Ausubel has listed some basic tenets of ecological medicine [13]: "The first goal of medicine is to establish the conditions for health and wholeness, thus preventing disease and illness. The second goal is to cure. The earth is also the physician's client. The patient under the physician's care is one part of the earth. Humans are part of a local ecosystem. Following the ecopsychological insight that a disturbed ecosystem can make people mentally ill, a disturbed ecosystem can surely make people physically ill. Medicine should not add to the illnesses of humans or the planet. Medical practices themselves should not damage other species or the ecosystem."

Until recently, with their focus on therapeutic medicine, health care providers and institutions were largely unaware of the public health and environmental impacts of their practices. It seems the time to integrate the environment into the already existing biopsychosocial concept of medicine [14]. Now, with increasing demands that health care institutions take responsibility for 
practices that degrade ecosystems and damage the health of humans and other species, that is beginning to change. The challenge is to minimize adverse impacts through reduction of natural resources and materials use, closed loop manufacturing and recycling processes, increased energy efficiency and use of renewable energy sources, and attending to entire product life cycles, while continuing to provide high quality patient care [14-16].

Roger Williams' seminal work Biochemical Individuality: The Basis for the Genetotrophic Concept was published as early as 1956, but it was not until the completion of the human genome project that we acquired a window into genomic individuality and its effects on health. The window is still small, but already we know that common genetic polymorphisms can dramatically influence our ability to detoxify exogenous chemicals, and that such variations can increase the probability of allergies and sensitivities more than ten-fold. Failure to excrete toxins can also predispose to heart disease, cancer and most of the diseases of the modern age.

Because advances in the field of psychosocial medicine have increased the complexity of our work, I feel that the name of this discipline should be changed. I suggest a more pragmatic term, namely, ecological medicine. Ecological medicine is a science relating to physiological, biological, genetic, socioeconomic, cultural, etc., changes now taking place in our cosmos. It is concerned with disease and health processes of several components of the living organism. Its task is to recognize, evaluate, prevent, and treat all the above variables which are an integral part of the disease process. I should like to stress here that the central thinking must be a strategic one: to devise and apply means, ways, and methods for the exchange of information between those working in clinical and humanistic disciplines and of those in laboratories. In other words, I, personally, believe that the research scientists who are working in any laboratory cannot afford to ignore the psychological, socioeconomic and cultural factors affecting people's health. Consequently, they must, on one hand, orient themselves in accordance with the above-mentioned demands, and, on the other, collaborate with scientists of the humanistic disciplines. Thus, only in this way can the anthropos be thoroughly and completely investigated as a unique psychophysiological, socioeconomic, and cultural ecological entity.

\section{View to the future}

Ecological medicine is based on the precautionary principle, which is the idea that a new technology should be presumed guilty until proven innocent. The counter-principle, which industry and technology (including the medical-industrial complex) have been using, is called the "risk paradigm". This paradigm says that it is the burden of society to prove that a new technology or substance is harmful. This model assumes that there are "acceptable" risks outweighed by the benefits of the new technology. Usually, we are so taken by the upside that is foisted upon us by the people who will directly profit from the technology that we tend to not want to think about the downside, which is unknown until it arises many years later, when it is much more difficult to retrieve what has been unleashed.

The implications of ecological health for medicine are considered in relation to the development of diagnostic and therapeutic practices, professional training programmes, and health policies implemented at municipal, state, and national levels $[17,18]$. By influencing the training and practices of healthcare professionals and the decisions of corporate and community leaders, the already existing biopsychosocial medicine can expand the scope and impact of future interventions beyond the health gains achievable through provision of direct services to patient populations [19].

\section{Conclusions}

Personnel of health care facilities have not routinely considered the environmental and public health impacts of their practices as they strive to provide high quality medical care. In part, this reflects a lack of attention to the connection between environmental factors and human health, a blind spot that is in no way unique to the health care sector. But it also reflects a cultural divide between clinical medicine and public health practice that developed over 100 years ago. As health care facilities increase, their focus on environmental performance they may then begin to participate more fully in the sustainable use of natural resources and sharply reduce adverse impacts on ecosystems, including people and wildlife. This is not an alternative concept, but should be integrated into the medicine that we learn in our studies in the (classical) university medical school. This effort will begin to provide much needed leadership toward integrating clinical medicine with public and environmental health. Education of different players in this context may be one of the most important ways to achieve success.

\section{References}

1. Schaller BJ, Gruber R, Merten HA, et al. Piezoelectric bone surgery: a revolutionary technique for minimally invasive surgery in cranial base and spinal surgery? Technical note. Neurosurgery 2005; 57 (4 Suppl): E410. 
2. Sandu N, Schaller B. Stem cell transplantation in brain tumors: a new field for molecular imaging? Mol Med 2010; 16: 433-7.

3. Schaller B. Educational attainment and risk of stroke and myocardial infarction. Med Sci Monit 2003; 9: LE27.

4. Sandu N, Schaller B. The trigemino-cardiac reflex: a view to the future. Arch Med Sci 2010; 6: 138-9.

5. Schaller BJ. The role of endothelin in stroke: experimental data and underlying pathophysiology. Arch Med Sci 2006; 2: 146-58.

6. Matusik E, Wajgt A, Janowska J, Zahorska-Markiewicz B, Schaller B, Zych-Twarderwaska E. Cell adhesion molecular markers in ischaemic stroke patients: correlation with clinical outcome and comparison with primary autoimmunie disease. Arch Med Sci 2009; 5: 182-9.

7. Narva M, Nevala R, Poussa T, Korpela R. The effect of Lactobacillus helveticus fermented milk on acute changes in calcium metabolism in postmenopausal women. Eur J Nutr 2004; 43: 61-8.

8. Narva M, Kärkkäinen M, Poussa T, Lamberg-Allardt C, Korpela R. Caseinphosphopeptides in milk and fermented milk do not affect calcium metabolism acutely in postmenopausal women. J Am Coll Nutr 2003; 22: 88-93.

9. Schaller B. Strategies for molecular imaging dementia and neurodegenerative disease. Neuropsychiatr Dis Treat 2008; 4: 585-612.

10. Belachew DA, Schaller BJ, Guta Z. Cervical spondylosis. A literature review with attention to the African population. Arch Med Sci 2007; 3: 315-22.

11. White F, Nanan D. Community health case studies selected from developing and developed countries - common principles for moving from evidence to action. Arch Med Sci 2008; 4: 358-63.

12. Ford LA, Crabtree RD, Habbell A. Crossing borders in health communication research: toward an ecological understanding of context, complexity, and consequences in community-based health education in the U.S.-Mexicoborderland. Health Commun 2009; 24: 608-18.

13. Ausubel $\mathrm{K}$. When healing becomes a crime: the amazing story of the hoxsey cancer clinics and the return of alternative therapies. Healing Arts Press; 1 edition 2000.

14. Crosby R, Noar SM. Theory development in healthy promotion: are we there yet? J Behav Med 2010; 33: 259-63.

15. Rahmati-Roodsari M, Shadnia S, Abdollahi M. Druginduced skin events in hospitalized patients in Tehran, Iran: a 6-year case series study. Arch Med Sci 2009; 5: 91-6.

16. Lee A, Ho M, Keung V. Healthy school as an ecological model for preventing of childhood obesity. Res Sports Med 2010; 18: 49-61.

17. Schaller B. Medical education and the Bologna Process. Arch Med Sci 2007; 3: 3-4.

18. Belachew DA, Zebenigus M, Schaller B, Guta Z. Neurology training and practice in Ethiopia. Sudanese J Public Health 2008; 3: 50-60.

19. Fleming ML, Tenkate T, Gould T. Ecological sustainability: what role for public health education? Int I Enivron Res Public Health 2009; 6: 2028-40. 